\title{
Alteration of cerebral perfusion and cortical thickness in depression episodes: a comparative MRI study
}

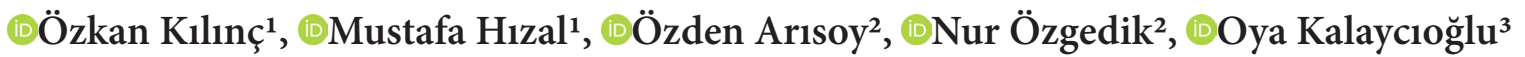 \\ ${ }^{1}$ Abant İzzet Baysal University, Faculty of Medicine, Department of Radiology, Bolu, Turkey \\ ${ }^{2}$ Abant İzzet Baysal University, Faculty of Medicine, Department of Psychiatry, Bolu, Turkey \\ ${ }^{3}$ Abant İzzet Baysal University, Faculty of Economics and Administrative Sciences, Department of Econometrics, Bolu, Turkey
}

Cite this article as: Kılınç Ö, Hızal M, Arıcan Ö, Özgedik N, Kalaycıoğlu O. Alteration of cerebral perfusion and cortical thickness in depression episodes: a comparative MRI study. J Health Sci Med 2022; 5(1): 38-44.

\begin{abstract}
Aim: We aimed to determine the difference between cerebral perfusion and cortical thickness between first attack and recurrent in major depression patients.

Material and Method: Our study was conducted prospectively between 01.03.2017-03.03.2018 in İzzet Baysal University Department of Psychiatry. 40 patients (21 first episodes and 19 recurrent episodes) diagnosed with depression according to DSM 5 by the American Psychiatric Association and a control group of 16 healthy individuals were evaluated for cerebral blood flow and cortical thickness with Perfusion MRI. Patients were also evaluated by Hamilton depression rating scale.

Findings: The cortical thickness was significantly decreased in recurrent attacks. There was no significant difference of $\mathrm{CBF}$ in first episode and recurrent episodes, except cingulate cortex, which showed significantly reduced CBF values in recurrent group. In patients with higher Hamilton depression scale points, the CBF values of insular cortex were decreased.

Conclusion: These findings suggests that cortical atrophy and activation of default mode network in recurrent episodes which leads to decreased response to treatment.
\end{abstract}

Keywords: Depression, cerebral perfusion, cortical thickness, MRI

\section{INTRODUCTION}

Major depression (MD) is a common and episodic disorder, which often causes a significant functional loss and even death due to suicide $(1,2)$. It is possible to improve the quality of life of MD patients with a correct diagnosis and treatment. There are many neuroimaging studies evaluating the pathophysiological process of depression using different imaging modalities (3-5). Positron emission tomography (PET), single photon emission computed tomography (SPECT), computed tomography (CT) angiography and perfusion magnetic resonance imaging (MRI) were often used to evaluate cerebral blood flow $(6,7)$ and some of these reports showed alterations in both the cerebral blood flow and cortical thickness in MD patients compared to healthy controls (HC) (8-10). The decrease in cortical thickness and limbic system volume was found to be associatied with the number of the depression episodes in some of these reports (10-12). Decreased blood flow to cerebral cortical regions, such as frontal, cingulate and thalamic cortices, were reported to be associated with depression and increased episode rate (13-15). The purpose of this study was to determine whether there was a difference in cerebral blood flow and cortical thickness between the first and recurrent depressive episode patients compared to healthy controls.

\section{MATERIAL AND METHOD}

The study was carried out with the permission of Clinical Researches Ethics Committee of Bolu Abant İzzet Baysal University (Date: 09.03.2017, Decision No: 2017/31). All procedures were carried out in accordance with the ethical rules and the principles of the Declaration of Helsinki.

\section{Participants}

40 major depression patients who applied to psychiatry clinic of our hospital between 01.03.2017-01.03.2018 were enrolled in the study and diagnosed with a semistructured clinical interview (SCID-I) according to DSM-IV criteria by an expert psychiatrist of at least 4 
years of experience. 21 of these patients were in their first depressive episode and 19 of them had recurrent depressive episodes. Patients under antidepressant treatment, with a diagnosis of psychiatric disorder other than major depression, with a poor cognitive performance, with a sleep disorder, with a history of alcohol and drug abuse, with a diagnosis of other medical disorders which might affect cerebral blood flow or cortical thickness (infections, neoplasms, traumatic brain injury, demyelinating diseases, hypertension, stroke, vasculitis, diabetes mellitus), with a contradiction to MRI scanning (pacemaker, MRI incompatible implants, claustrophobia, physical deformation which do not allow patient to get into MRI device), and patients below 18 or above 60 years of age were excluded from the study. The control group consisted of 16 healthy subjects with the same exclusion criteria. Depression severity of the patients and controls were evaluated with Hamilton Depression Rating Scale (HDRS).

\section{Image Acquisition and Data Analysis}

Imaging was made in a 1.5 Tesla MRI machine (Symphony; Siemens Medical Systems, Erlangen, Germany). A head and/or neck surface coil was used. Participants in first, recurrent episode and control groups underwent MRI to obtain isovolumetric 3D T1 MPRAGE on sagittal plane (TR: 2400, TE: 3.61, FOV: 240x100, slice thickness: 1.2 $\mathrm{mm}$ ) prior to contrast medium administration. After the contrast medium (Gadovist $15 \mathrm{ml}, 01 . \mathrm{mmol} / \mathrm{kg}$, injection rate $3 \mathrm{ml} / \mathrm{sn}$ prior to $20 \mathrm{ml}$ SF push), GE T2* DSC perfusion sequence (TR:2410, TE: 47, FOV: 230x100, slice thickness $5 \mathrm{~mm}$ ) was obtained. MR images of patients were uploaded to a workstation (syngoMMWP VE25A, Siemens AG, Berlin and Munich, Germany) for evaluations and measurements.

The thickness of bilateral prefrontal, insular, parahippocampal and cingulate cortices were measured using the T1 MPRAGE images on the axial plane. rCBF values of the same regions were measured in the axial plane of $\mathrm{rCBF}$ map generated in the workstation with a region of interest smaller than $1.5 \mathrm{~cm} 2$. A radiologist with at least 5 years of experience made the radiologic evaluation.

\section{Statistical Analysis}

The normality of $\mathrm{rCBF}$ and cortical thickness measurements for each location in different groups was tested with the Shapiro-Wilk normality test. Normally distributed $\mathrm{rCBF}$ and cortical thickness data were compared with one way ANOVA test and posthoc comparisons were done using Bonferroni correction. Non-normal distributed data were compared with Kruskal Wallis ANOVA test.
According to normal distribution, either Mann Whitney $U$ test or student $t$ test was used to compare the data between the two groups. The relation between rCBF, cortical thickness, depression severity, number of depressive episodes was analyzed with Pearson correlation analysis. Statistical significance was accepted as 0.05 in all statistical tests. The differences between the groups were also summarized with boxplots.

\section{RESULT}

There was no significant difference in the cortical thickness and $\mathrm{rCBF}$ values between the right and left hemispheres for all locations. The mean $\mathrm{rCBF}$ value in the right and left parahippocampal cortex were $9.9 \mathrm{ml} /$ min and $9.8 \mathrm{ml} / \mathrm{min}$ in HC's; $12.9 \mathrm{ml} / \mathrm{min}$ and $13.1 \mathrm{ml} /$ $\mathrm{min}$ the first episode group and 14.2 and $15.0 \mathrm{ml} / \mathrm{min}$ in the recurrent episode group. The mean $\mathrm{rCBF}$ value in the right and left prefrontal cortex were $13.8 \mathrm{ml} / \mathrm{min}$ and $13.7 \mathrm{ml} / \mathrm{min}$ in HC's; $22.0 \mathrm{ml} / \mathrm{min}$ and $25.1 \mathrm{ml} / \mathrm{min}$ in the first episode group and $17.5 \mathrm{ml} / \mathrm{min}$ and $17.9 \mathrm{ml} / \mathrm{min}$ in the recurrent episode group. The mean $\mathrm{rCBF}$ values in the right and left insular cortex were $12.6 \mathrm{ml} / \mathrm{min}$ and $12.7 \mathrm{ml} / \mathrm{min}$ in HC's; $22.8 \mathrm{ml} / \mathrm{min}$ and $21.6 \mathrm{ml} / \mathrm{min}$ in the first episode group and $19.6 \mathrm{ml} / \mathrm{min}$ and $18.6 \mathrm{ml} / \mathrm{min}$ in the recurrent episode group. The mean $\mathrm{rCBF}$ values in the right and left cingulate cortex were $10.0 \mathrm{ml} / \mathrm{min}$ and $8.5 \mathrm{ml} / \mathrm{min}$ in HC's; $21.2 \mathrm{ml} / \mathrm{min}$ and $21.6 \mathrm{ml} / \mathrm{min}$ in the first episode group and $13.6 \mathrm{ml} / \mathrm{min}$ and $13.7 \mathrm{ml} / \mathrm{min}$ in the recurrent episode group. The control group had the lowest $\mathrm{rCBF}$ values for each location.

The mean $\mathrm{rCBF}$ of the parahippocampal area was lower than the other regions in the first episode group $(\mathrm{p}<0.05)$. The lowest mean $\mathrm{rCBF}$ was in the parahippocampal area (13.04 \pm 6.17$)$ and the highest mean $\mathrm{rCBF}$ was in the prefrontal cortex $(23.60 \pm 13.60)$ in the first episode group. When the locations were compared in pairs, rCBF measurements in the parahippocampal cortex in the first episode group was found to be lower than the measurements in the prefrontal cortex and insular cortex locations ( $\mathrm{p}$ values, 0.003 and 0.002 , respectively).

In the recurrent episode group, the lowest mean $\mathrm{rCBF}$ value was in the cingulate cortex $(13.67 \pm 5.18)$; while the highest mean $\mathrm{rCBF}$ value was in the insular cortex $(19.13 \pm 7.65)$ but, there was no significant difference between the mean $\mathrm{rCBF}$ values of the different locations in the recurrent episode group ( $\mathrm{p}=0.059)$.

When the mean $\mathrm{rCBF}$ values of the first episode group was compared with the recurrent episode group, the mean $\mathrm{rCBF}$ values were lower in the prefrontal, cingular and insular cortices in the recurrent episode group compared to the first episode group but, a significant difference was found only in the cingulate cortex region $(\mathrm{p}<0.05)$ (Figure 1). 


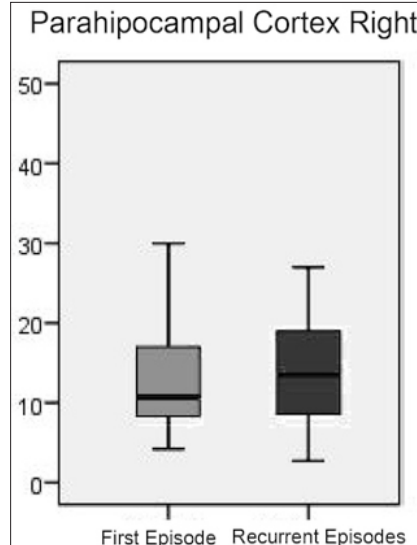

Insular Cortex Right

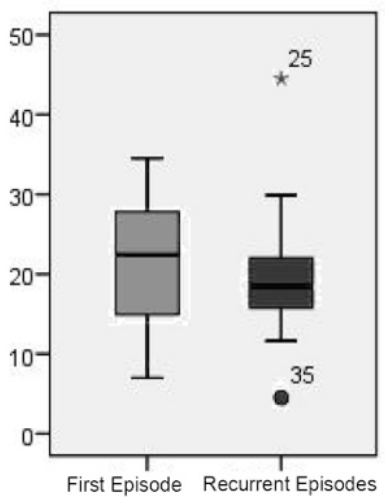

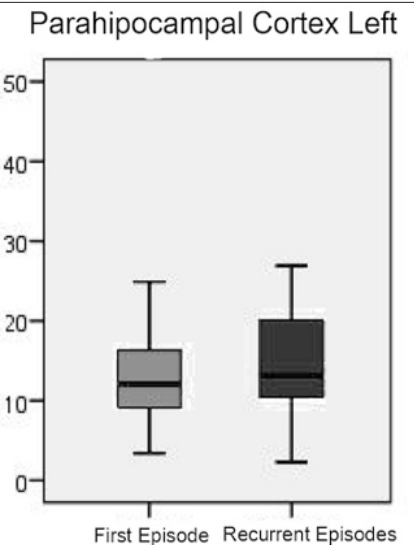

Insular Cortex Left

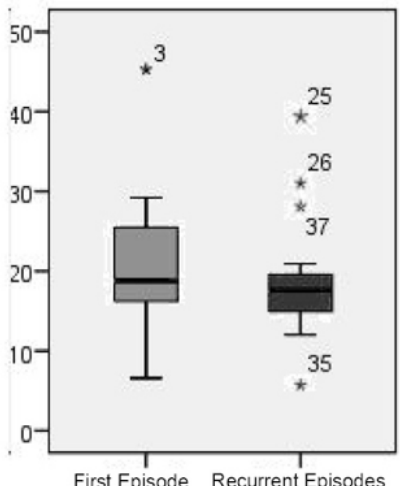

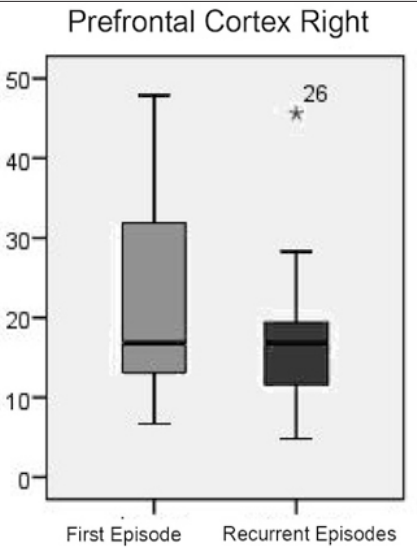

Cingulate Cortex Right

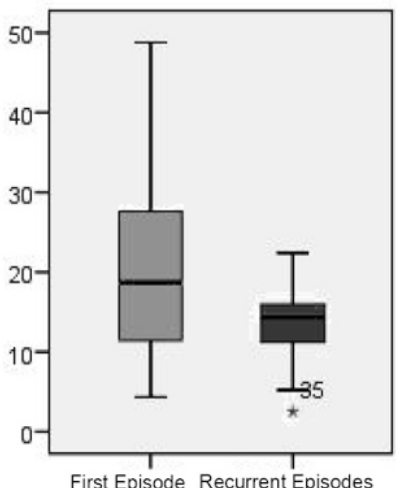

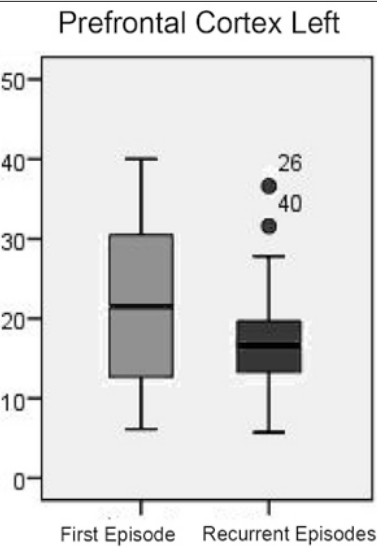

Cingulate Cortex Left

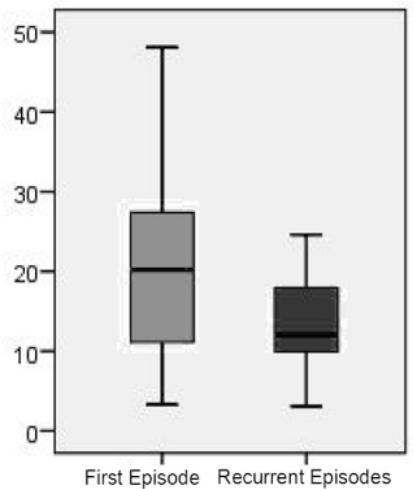

Figure 1. Comparing box plots of mean rCBF values of each location in first and recurrent episode groups. Note: regional cerebral blood flow $(\mathrm{rCBF})$ value is expressed in $\mathrm{ml} / \mathrm{min}$.

In the first episode patient group, there was a significant positive correlation between $\mathrm{rCBF}$ value of the right prefrontal cortex and the Hamilton depression scale score $(p<0.05)$. In the recurrent depression group, a significant negative correlation was found between $\mathrm{rCBF}$ value of the left insular cortex and the Hamilton depression scale score $(\mathrm{p}=0.040)$ (Table 1).

\begin{tabular}{|c|c|c|c|c|}
\hline Region & $\begin{array}{l}\text { Healthy } \\
\text { control }\end{array}$ & $\begin{array}{l}\text { First episode } \\
\text { group }\end{array}$ & $\begin{array}{l}\text { Recurrent } \\
\text { episode } \\
\text { group }\end{array}$ & $\mathbf{P}$ \\
\hline \multicolumn{5}{|c|}{ Parahippocampus } \\
\hline Right & $9.90 \pm 5.92$ & $12.91 \pm 7.06$ & $14.24 \pm 7.01$ & 0.144 \\
\hline Left & $9.81 \pm 5.41$ & $13.17 \pm 5.95$ & 15.096 .66 & 0.081 \\
\hline Mean & $9.86 \pm 5.60$ & $13.04 \pm 6.17$ & $14.67 \pm 6.43$ & 0.096 \\
\hline \multicolumn{5}{|c|}{ Prefrontal cortex } \\
\hline Right & $13.86 \pm 89.7^{a}$ & $22.05 \pm 12.26^{\mathrm{a}}$ & $17.52 \pm 8.90$ & $0.027^{\star}$ \\
\hline Left & $13.71 \pm 7.45^{\mathrm{a}}$ & $25.15 \pm 15.70^{\mathrm{ab}}$ & $17.95 \pm 7.55^{\mathrm{b}}$ & $0.002^{*}$ \\
\hline Mean & $13.79 \pm 80.40^{\mathrm{a}}$ & $23.60 \pm 13.60^{\mathrm{a}}$ & $17.74 \pm 8.09$ & $0.006^{*}$ \\
\hline \multicolumn{5}{|l|}{ Insula } \\
\hline Right & $12.61 \pm 8.53^{\mathrm{a}}$ & $23.87 \pm 14.00^{\mathrm{a}}$ & $19.64 \pm 8.24$ & $0.007^{\star}$ \\
\hline Left & $12.78 \pm 8.50^{\mathrm{a}}$ & $21.58 \pm 11.32^{\mathrm{a}}$ & $18.62 \pm 7.49$ & $0.017^{\star}$ \\
\hline Mean & $12.70 \pm 8.41^{\mathrm{a}}$ & $22.72 \pm 12.56^{\mathrm{a}}$ & $19.13 \pm 7.65$ & $0.009^{*}$ \\
\hline \multicolumn{5}{|c|}{ Cingulate cortex } \\
\hline Right & $10.02 \pm 7.00^{\mathrm{a}}$ & $21.20 \pm 12.50^{\mathrm{ab}}$ & $13.62 \pm 5.03^{\mathrm{b}}$ & $<0.001^{*}$ \\
\hline Left & $8.47 \pm 5.69^{\mathrm{a}}$ & $21.60 \pm 11.90^{\mathrm{ab}}$ & $13.73 \pm 5.93^{b}$ & $<0.001^{*}$ \\
\hline Mean & $9.38 \pm 6.28^{\mathrm{a}}$ & $21.39 \pm 12.60^{\mathrm{ab}}$ & $13.67 \pm 5.18^{\mathrm{b}}$ & $<0.001^{*}$ \\
\hline $\begin{array}{l}\text { Values are } \\
\text { expressed i } \\
\text { at } \alpha<0.05 \text {. } \\
\text { post-hoc c }\end{array}$ & $\begin{array}{l}\text { Is (standart devia } \\
\text { /min, p values ob } \\
\text { ne superscript lett }\end{array}$ & $\begin{array}{l}\text { o), regional cerebra } \\
\text { ined from One-way } \\
\text { indicates statistical }\end{array}$ & $\begin{array}{l}\text { lood flow }(\mathrm{rCBF}) \\
\text { NOVA test }{ }^{*} \mathrm{p} \text { s }\end{array}$ & $\begin{array}{l}\text { value is } \\
\text { nificant } \\
\text { nce in the }\end{array}$ \\
\hline
\end{tabular}

There were no significant differences between the cortical thickness of all localizations in the first episode group and the control group ( $p>0.05)$ (Table 2). However, the cortical thickness of all localizations of the recurrent episode group was significantly lower than both the first episode group and the control group $(\mathrm{p}<0.05)$ (Figure 2).

Table 2. Correlation between rCBF measurements of different locations and Hamilton depression rating scale score of the first episode and recurrent episode patient groups

\begin{tabular}{|lcccc|}
\hline Location & \multicolumn{2}{c}{$\begin{array}{c}\text { First Episode } \\
\text { Group }(\mathbf{n}: 21)\end{array}$} & \multicolumn{2}{c|}{$\begin{array}{c}\text { Recurrent Episode } \\
\text { Group (n:19) }\end{array}$} \\
\cline { 2 - 5 } & $\mathbf{r}$ & $\mathbf{p}$ & $\mathbf{~ r}$ & $\mathbf{p}$ \\
\hline Right Parahippocampal & 0.345 & 0.125 & -0.244 & 0.314 \\
Left Parahippocampal & 0.247 & 0.280 & -0.176 & 0.470 \\
Right Prefrontal & $0.434^{*}$ & 0.0049 & -0.113 & 0.646 \\
Left Prefrontal & 0.361 & 0.108 & -0.046 & 0.853 \\
Right Insular & 0.325 & 0.151 & -0.423 & 0.072 \\
Left Insular & 0.331 & 0.143 & $-0.474^{*}$ & 0.040 \\
Right Cingulate & 0.248 & 0.279 & -0.074 & 0.762 \\
Left Cingulate & 0.123 & 0.596 & -0.062 & 0.802 \\
\hline Pearson's correlation analysis, ${ }^{*}$ correlation coefficients significant at $\alpha=0.05$. \\
\hline \multicolumn{5}{c}{} \\
\hline
\end{tabular}




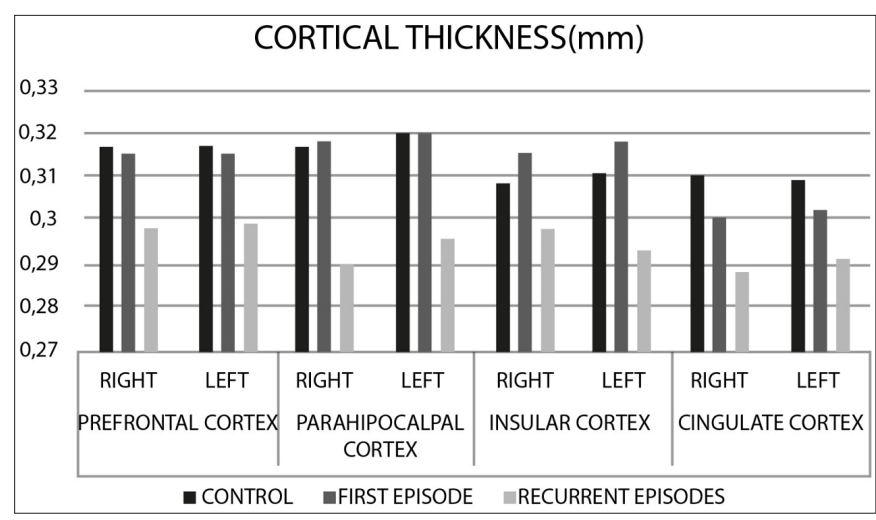

Figure 2. Mean cortical thickness values of the locations in each group. Note: Value of cortical thickness is expressed in $\mathrm{mm}$.

Table 3. Comparison of the cortical thickness values of the groups

\begin{tabular}{|c|c|c|c|}
\hline Location & Groups & $\begin{array}{l}\text { Mean cortical } \\
\text { thickness }(\mathrm{mm})\end{array}$ & $p$ value \\
\hline \multirow{3}{*}{$\begin{array}{l}\text { Right } \\
\text { Parahippocampal }\end{array}$} & Control & 0.318 & \multirow{3}{*}{$0.003^{*}$} \\
\hline & First episode & 0.317 & \\
\hline & Recurrent episode & 0.290 & \\
\hline \multirow{3}{*}{$\begin{array}{l}\text { Left } \\
\text { Parahippocampal }\end{array}$} & Control & 0.320 & \multirow{3}{*}{$<0.001^{\star}$} \\
\hline & First episode & 0.319 & \\
\hline & Recurrent episode & 0.297 & \\
\hline \multirow{3}{*}{ Right Prefrontal } & Control & 0.317 & \multirow{3}{*}{$0.010^{*}$} \\
\hline & First episode & 0.314 & \\
\hline & Recurrent episode & 0.298 & \\
\hline \multirow{3}{*}{ Left Prefrontal } & Control & 0.318 & \multirow{3}{*}{$0.010^{*}$} \\
\hline & First episode & 0.314 & \\
\hline & Recurrent episode & 0.299 & \\
\hline \multirow{3}{*}{ Right Insular } & Control & 0.309 & \multirow{3}{*}{$0.028^{\star}$} \\
\hline & First episode & 0.316 & \\
\hline & Recurrent episode & 0.298 & \\
\hline \multirow{3}{*}{ Left Insular } & Control & 0.311 & \multirow{3}{*}{$0.002^{\star}$} \\
\hline & First episode & 0.317 & \\
\hline & Recurrent episode & 0.294 & \\
\hline \multirow{3}{*}{ Right Cingulate } & Control & 0.311 & \multirow{3}{*}{$0.008^{\star}$} \\
\hline & First episode & 0.299 & \\
\hline & Recurrent episode & 0.288 & \\
\hline \multirow{3}{*}{ Left Cingulate } & Control & 0.309 & \multirow{3}{*}{$0.025^{\star}$} \\
\hline & First episode & 0.300 & \\
\hline & Recurrent episode & 0.293 & \\
\hline
\end{tabular}

\section{DISCUSSION}

The mean $\mathrm{rCBF}$ value of the cingulate cortex was found to be significantly lower in the recurrent episode group compared to the first episode group and the cortical thickness were found to be significantly lower in all locations in the recurrent episode group compared to both first episode group and the control group.

There are studies that report a decrease in volume in certain cerebral regions in patients with depression. It was reported that there was a decreased right and left hippocampal volume in recurrent depressive patients (8). It was also stated that there were structural changes in the hippocampus at the first episode, however there was no change in the volume. They additionally stated that the volume loss was added to this shape disorder with recurrent episodes $(10,11)$. Those reports were consistent with the results of this study, which showed significantly decreased thickness in the parahippocampal cortices in the recurrent episode group compared to control and first episode groups. Less hippocampal shrinkage was reported in patients responding to treatment (12).

Structural MRI studies in patients with depression were reviewed and it was reported that shrinkage in the prefrontal, anterior cingulate and orbitofrontal cortex was greater than the hippocampus in two different studies. These findings suggest that frontal and cingulate cortex may play a role as hippocampus in the pathophysiology of depression $(16,17)$. Volume reductions were detected in subcortical structures and cortical brain structures, such as the anterior cingulate cortex and the prefrontal cortex, which have an important role in cognitive function (18). It was reported that the frontal lobe was $7.2 \%$ smaller in patients with depression than in healthy controls (9). We also detected a reduction in cortical thickness in prefrontal, cingulate and insular cortex in recurrent episode group in comparison to the remaining two groups. There are also studies reporting that volume loss in depression-related structures may be hereditary; however, further studies on this subject are necessary $(19,20)$.

Cortical thinning is thought to occur with recurrent episodes due to intermittent and continuous changes in $\mathrm{rCBF}$ values. Excessive activity of the limbic system, which plays an active role in anxiety and depression, might induce hypothalamic-pituitary-adrenal axis, which in turn might cause an increase in glucocorticoid release and a decrease in volume (21-23). In addition, depression and chronic stress might cause an increase in proinflammatory cytokines leading to a decrease in serotonergic transmission and a reduction in brainderived-neurotrophic factor synthesis through the activation of hypothalamic-pituitary adrenal axis which results in neuronal apoptosis and glial damage (24). It was reported that frontal hypoperfusion was due to a decrease in glutamate, glutamine and gamma aminobutyric acid levels and this resulted in a decrease in frontal neuronal size and glial cell density (14). Emotion blunting in depression was associated with a decrease in frontal neuronal size and glial cell density due to hypoperfusion and with treatment, an improvement was seen in these hypoperfused areas (25-28).

In previous studies, it was reported that neurochemical impairment due to hypoperfusion was effective in the development of depression (29-33). A decrease of $\mathrm{rCBF}$ primarily in the left hemisphere, specifically 
in the left temporal lobe, left prefrontal cortex and left anterior cingulate cortex was reported in patients with depression compared to healthy individuals $(4,13,21,29)$. It was also reported decreased cortical perfusion in bilateral frontal regions and bilateral thalamic regions in patients with refractory depressive disorder (RDB) and in the left prefrontal cortex in patients with nonrefractory depressive (NRD) disorder (14). Decreased blood flow in the cingulate cortex leads to a deterioration in the regulation of emotion and a decrease in patient motivation and an increase in depression. It may also lead to an increased number of recurrent episodes (15). In our study, there was also significant reduction in $\mathrm{rCBF}$ value of the cingulate cortex in the recurrent group compared to the first episode group. Probably this decreased blood flow might cause a loss of function of the cingulate cortex and thus contribute to the formation of depressive symptoms through emotion dysregulation.

Also, a significant positive correlation between right prefrontal cortex $\mathrm{rCBF}$ value and total depression score was found in the first episode patient group. Predominantly increased $\mathrm{rCBF}$ in the right hemisphere, specifically in the right cerebellum, thalamus, frontal lobe and anterior cingulate cortex in depressed patients compared to healthy controls was reported in previous studies $(3,21)$. Right hemisphere is mostly responsible for processing negative emotions and it was shown to be activated by negative facial cues (34). So, in more severely depressed patients a greater right prefrontal cortex activity might be seen as in our study. But besides that, blood flow might be increased in the right prefrontal cortex in order to protect neurons in the first episode group.

In addition, there was a significant negative correlation between $\mathrm{rCBF}$ value of the left insular cortex and total depression score in the recurrent depressive patients. Anterior insula and the cingulate cortex is part of the salince network ( $\mathrm{SN})$ and it is an internal hub mediating the interactions between central executive network (CEN) and default mode network (DMN) (35). It plays an active role in activating CEN and deactivating DMN (36). DMN is activated during tasks involving autobiographicalepisodic memory, self-referential processes including self-monitoring and social cognitive processes related to self and others. The decreased blood flow to insula might cause an activation of the DMN resulting in overthinking about self, past relations and events with others in recurrent depressed patients. If this remembering and rumination is about mostly negative events this might cause an increase in depressive symptoms. In addition, decreased activity in insula might cause a deactivation of the CEN which is mostly involved in working memory, judgement and decision making in the context of goal- directed behavior. Thus, deactivation of CEN might result in a deterioration in the above mentioned cognitive functions.

In our study, rCBF values of bilateral cingulate cortex and insula and bilateral cingulate and insular cortical thickness were significantly decreased in recurrent attack patients. Because of the decrease in the blood flow and thickness of the insular and cingulate cortex, the DMN might remain active and the excitations might not be able to be forwarded to CEN, which might lead to a decreased production of appropriate behavioral responses to salient stimuli and an increase in ruminative thoughts about the past so that the effects of depression may become more resistant and severe. In addition, the decreased cortical thickness of the prefrontal and parahippocampal cortices and the decreased $\mathrm{rCBF}$ in the right prefrontal cortex in the recurrent episode patient group is consistent with the fact that cognitive functions, especially executive functions related to prefrontal activity and memory related to parahippocampal activity, can be more impaired in patients with recurrent attacks.

The main limitation in our study was the small number of patients. Apart from the depression in the patients, the exact distinctions of the pathologies that disrupted the brain flow could not be made and they were excluded according to the anamnesis of the patients. Since our study was cross-sectional, it was not possible to determine whether patients with first episode would be re-attacked in the following period and blood flows and cortical thicknesses could not be followed-up prospectively.

\section{CONCLUSION}

As a result, our findings showed that the cortical thickness decreased significantly in the recurrent episode group although it was not different in the first episode group compared to healthy controls, suggesting that prevention of recurrence of depression is a must in order to preserve brain health. The lower rCBF values in the bilateral cingulate cortex in the recurrent episode patients compared to first episode patients and the negative correlation between the left insular cortex CBF values and depression score in the recurrent episode group might suggest that the salience network which regulate the dynamic interactions between the large scale networks of DMN and CEN seem to be affected by depression episodes.

\section{ETHICAL DECLARATIONS}

Ethics Committee Approval: The study was carried out with the permission of Clinical Researches Ethics Committee of Bolu Abant İzzet Baysal University (Date: 09.03.2017, Decision No: 2017/31). 
Informed Consent: Because the study was designed retrospectively, no written informed consent form was obtained from patients.

Referee Evaluation Process: Externally peer-reviewed.

Conflict of Interest Statement: The authors have no conflicts of interest to declare.

Financial Disclosure: This work was supported by the Instutional Scientific Research Project Committee (grant number: 2017.08.34.1236). We would like to thank to and for their help in data acquisition.

Author Contributions: All of the authors declare that they have all participated in the design, execution, and analysis of the paper, and that they have approved the final version.

Note: This study orally presented at $6^{\text {th }}$ International Medical and Health Sciences Research Congress, April 10-11, 2021, Ankara, Turkey

\section{REFERENCES}

1. Fava M, Kendler KS. Major depressive disorder. Neuron 2000; 28 : 335-41.

2. Frank E, Thase ME. Natural history and preventative treatment of recurrent mood disorders. Annu Rev Med 1999; 50: 453-68.

3. Chen XL, Xie JX, Han HB, Cui YH, Zhang BQ. MR perfusion weighted imaging and quantitative analysis of cerebral hemodynamics with symptom provocation in unmedicated patients with obsessive-compulsive disorder. Neurosci Lett 2004; 370: 206-11.

4. Chen MH, Li CT, Lin WC, et al. Persistent antidepressant effect of low-dose ketamine and activation in the supplementary motor area and anterior cingulate cortex in treatment-resistant depression: A randomized control study. J Affect Disord 2018; 225: 709-14.

5. Clark CP, Brown GG, Archibald SL, et al. Does amygdalar perfusion correlate with antidepressant response to partial sleep deprivation in major depression? Psychiatry Res 2006; 146: 43-51.

6. Greenberg PE, Fournier AA, Sisitsky T, Pike CT, Kessler RC. The economic burden of adults with major depressive disorder in the United States. J Clin Psychiatry 2015; 76: 155-62.

7. Andrade L, Caraveo-Anduaga JJ, Berglund P, et al. The epidemiology of major depressive episodes: results from the International Consortium of Psychiatric Epidemiology (ICPE) Surveys. Int J Methods Psychiatr Res 2003; 12: 3-21.

8. Sheline YI, Sanghavi M, Mintun MA, Gado MH. Depression duration but not age predicts hippocampal volume loss in medically healthy women with recurrent major depression. J Neurosci 1999; 19: 5034-43.

9. Coffey CE, Wilkinson WE, Weiner RD, et al. Quantitative cerebral anatomy in depression: a controlled magnetic resonance imaging study. Arch Gen Psychiatry 1993; 50: 7-16.

10. Posener JA, Wang L, Price JL, et al. High-dimensional mapping of the hippocampus in depression. Am J Psychiatry 2003; 160: 83-9.

11. MacQueen GM, Campbell S, McEwen BS, et al. Course of illness, hippocampal function, and hippocampal volume in major depression. Proc Natl Acad Sci USA 2003; 100: 1387-92.

12. Frodl TS, Koutsouleris N, Bottlender R, et. al. Depression-related variation in brain morphology over 3 years: effects of stress. Arch Gen Psychiatry 2008; 65: 1156-65.
13. Hasler G, Van der Veen JW, Tumonis T, Meyers N, Shen J, Drevets WC. Reduced prefrontal glutamate/glutamine and $\gamma$-aminobutyric acid levels in major depression determined using proton magnetic resonance spectroscopy. Arch Gen Psychiatry 2007; 64: 193-200.

14.Lui S, Parkes LM, Huang X, et al. Depressive disorders: focally altered cerebral perfusion measured with arterial spin-labeling MR imaging. Radiology 2009; 25: 476-84.

15. Compton WM, Conway KP, Stinson FS, Grant BF. Changes in the prevalence of major depression and comorbid substance use disorders in the United States between 1991-1992 and 2001-2002. Am J Psychiatry 2006; 163: 2141-7.

16. Koolschijn P, Van Haren NE, Pol HEH, Kahn RS. Hypothalamus volume in twin pairs discordant for schizophrenia. Eur Neuropsychopharmacol 2008; 18: 312-5.

17. Koolschijn P, Van Haren NE, Lensvelt-Mulders GJ, Pol HEH, Hilleke E, Kahn RS. Brain volume abnormalities in major depressive disorder: A meta-analysis of magnetic resonance imaging studies. Hum Brain Mapp 2009; 30: 3719-35.

18. Aan het Rot M, Mathew SJ, Charney DS. Neurobiological mechanisms in major depressive disorder. CMAJ 2009; 180: 305 13

19.Schatzberg AF. Major depression: causes or effects? Am J Psychiatry 2002; 159: 1077-9.

20. Peterson BS, Warner V, Bansal R, et al. Cortical thinning in persons at increased familial risk for major depression. Proc Natl Acad Sci USA 2009; 106: 6273-8.

21. Fountoulakis KN, Iacovides A, Gerasimou G, et al. The relationship of regional cerebral blood flow with subtypes of major depression. Prog Neuropsychopharmacol Biol Psychiatry 2004; 28: 537-46.

22. Gold SM, Dziobek I, Rogers K, Bayoumy A, McHugh PF, Convit A. Hypertension and hypothalamo-pituitary-adrenal axis hyperactivity affect frontal lobe integrity. J Clin Endocrinol Metab 2005; 90: 3262-7.

23. Sargent PA, Kjaer KH, Bench CJ, et al. Brain serotonin $1 \mathrm{~A}$ receptor binding measured by positron emission tomography with [11C] WAY-100635: effects of depression and antidepressant treatment. Arch Gen Psychiatry 2000; 57: 174-80.

24. Pan W, Banks WA, Fasold MB, Blunth J, Kasten AJ. Transport of brain-derived neurotrophic factor across the blood-brain barrier. Neuropharmacology 1998; 37: 1553-61.

25. Cotter D, Mackay D, Chana G, Beasley C, Landau S, Everall IP. Reduced neuronal size and glial cell density in area 9 of the dorsolateral prefrontal cortex in subjects with major depressive disorder. Cereb Cortex 2002; 12: 386-94.

26. Matsuo K, Onodera Y, Hamamoto T, Muraki K, Kato N, Kato T. Hypofrontality and microvascular dysregulation in remitted late-onset depression assessed by functional near-infrared spectroscopy. Neuroimage 2005; 26: 234-42.

27. Fregni F, Ono C, Santos C, et al. Effects of antidepressant treatment with rTMS and fluoxetine on brain perfusion in PD. Neurology 2006; 66: 1629-37.

28. Teneback CC, Nahas Z, Speer AM, et al. Changes in prefrontal cortex and paralimbic activity in depression following two weeks of daily left prefrontal TMS. J Neuropsychiatry Clin Neurosci 1999; 11: 426-435.

29. Bench CJ, Friston KJ, Brown RG, Scott LC, Frackowiak RS, Dolan RJ. The anatomy of melancholia-focal abnormalities of cerebral blood flow in major depression. Psychol Med 1992; 22: 607-15.

30. Direk N, Koudstaal PJ, Hofman A, Ikram MA, Hoogendijk WJ, Tiemeier H. Cerebral hemodynamics and incident depression: the Rotterdam Study. Biol Psychiatry 2012; 72: 318-23.

31. Drevets WC, Price JL, Furey ML. Brain structural and functional abnormalities in mood disorders: implications for neurocircuitry models of depression. Brain Struct Funct 2008; 213: 93-118. 
32. Narushima K, Kosier J, Robinson RG. A reappraisal of poststroke depression, intra-and inter-hemispheric lesion location using meta-analysis. J Neuropsychiatry Clin Neurosci 2003; 15: 422-30.

33. Smith K, Morris J, Friston K, Cowen PJ, Dolan RJ. Brain mechanisms associated with depressive relapse and associated cognitive impairment following acute tryptophan depletion. Br J Psychiatry 1999; 174: 525-9.

34. Killgore WDS, Gruber SA, Yurgelun-Todd DA. Depressed mood and lateralized prefrontal activity during a Stroop task in adolescent children. Neurosci Lett 2007; 416: 43-8

35. Chand GB, Wu J, Hajjar I, Qiu D. Interactions of Insula Subdivisions Based Networks with Default-Mode and CentralExecutive Networks in Mild Cognitive Impairment. Front Aging Neurosci 2017; 9: 367.

36. Menon V, Uddin LQ. Saliency, switching, attention and control: a network model of insula function. Brain Struct Funct 2010; 214 655-67 